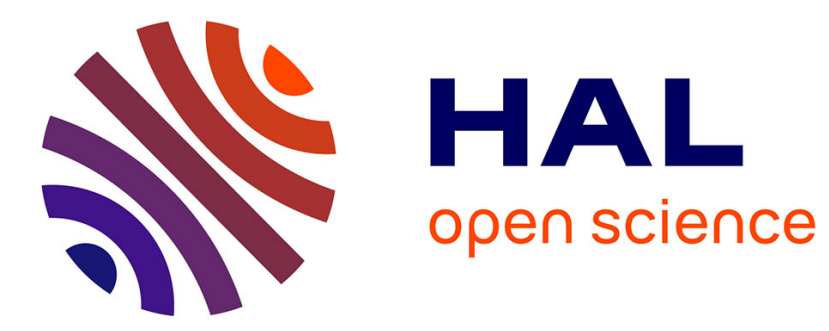

\title{
Electrodeposited biotinylated polypyrrole as an immobilization method for impedimetric immunosensors
}

Oussama Ouerghi, Ahmed Touhami, Nicole Jaffrezic-Renault, Claude Martelet, Hafedh Ben Ouada, Serge Cosnier

\section{- To cite this version:}

Oussama Ouerghi, Ahmed Touhami, Nicole Jaffrezic-Renault, Claude Martelet, Hafedh Ben Ouada, et al.. Electrodeposited biotinylated polypyrrole as an immobilization method for impedimetric immunosensors. IEEE Sensors Journal, 2004, 4 (5), pp.559-567. 10.1109/JSEN.2004.832858 . hal00140632

\section{HAL Id: hal-00140632 \\ https://hal.science/hal-00140632}

Submitted on 18 Apr 2007

HAL is a multi-disciplinary open access archive for the deposit and dissemination of scientific research documents, whether they are published or not. The documents may come from teaching and research institutions in France or abroad, or from public or private research centers.
L'archive ouverte pluridisciplinaire HAL, est destinée au dépôt et à la diffusion de documents scientifiques de niveau recherche, publiés ou non, émanant des établissements d'enseignement et de recherche français ou étrangers, des laboratoires publics ou privés. 


\title{
Electrodeposited Biotinylated Polypyrrole as an Immobilization Method for Impedimetric Immunosensors
}

\author{
Oussama Ouerghi, Ahmed Touhami, Nicole Jaffrezic-Renault, Claude Martelet, Hafedh Ben Ouada, and \\ Serge Cosnier
}

\begin{abstract}
The potentialities of an electrodeposited biotinylated polypyrrole film as an immobilization matrix for the fabrication of impedimetric immunosensors are described. Biotinylated antibody (anti-human IgG), used as a model system, was attached to free biotin groups on the electrogenerated polypyrrole film using avidin as a coupling reagent. The resulting recognition interface consisted of a highly oriented monolayer immobilized onto the polymer surface. Cyclic votammetry was used to characterize the polymer film. Additionally, scanning electron microscopy and atomic force microscopy were used to investigate the morphology of the immobilized material. This immobilization method allows the obtention of a highly reproducible and stable device. The resulting immunosensor has a linear dynamic range of 10-80 ng. $\mathrm{ml}^{-1}$ of antigen and a detection limit of $10 \mathrm{pg} \cdot \mathrm{ml}^{-1}$. Furthermore, this immunosensor exhibited minor loss in response after two regeneration steps.
\end{abstract}

Index Terms-Biotinylated polypyrrole, electropolymerization, immunosensor, impedance spectroscopy.

\section{INTRODUCTION}

D URING the past few years, immunosensors [1], [2] have been the subject of increasing interest, because of their potentialities in several fields, such as clinical diagnostics and environmental control. Owing to their low cost, small size, possible use in vitro and in vivo, and also their short response time, these devices can compete efficiently with the standard clinical diagnostic methods based on classical immunoasays.

Typically, antibodies specifically directed against the desired analyte (antigen) are immobilized on the transducer surface as

Manuscript received July 26, 2001; revised January 7, 2004. This work was supported in part by the Rhone-Alpes-Monastir cooperation program and in part by the CMCU program. The associate editor coordinating the review of this paper and approving it for publication was Dr. Krishna Persaud.

O. Ouerghi is with Ingénierie et Fonctionnalization des Surfaces, Ecole Centrale de Lyon, F-69134 Ecully, France, and also with the Laboratoire de Physique des Interfaces, Faculté des Sciences de Monastir-5000, Tunisia (e-mail: oussamaouerghi@yahoo.com).

A. Touhami is with the Physics Department, Dalhousie University, Halifax, NS B3H 4H6, Canada (e-mail: ahmed@Fizz.Phys.Dal.Ca).

N. Jaffrezic-Renault and C. Martelet are with Ingénierie et Fonctionnalization des Surfaces, Ecole Centrale de Lyon, F-69134 Ecully, France (e-mail: Nicole.Jaffrezic@ec-lyon.fr; Claude.Martelet@ec-lyon.fr).

H. Ben Ouada is with Laboratoire de Physique des Interfaces, Faculté des Sciences de Monastir-5000, Tunisia (e-mail: hafedh.bouada@ fsm.rnu.tn).

S. Cosnier is with Laboratoire d'Electrochimie Organique et de Photochimie Redox, Université Joseph Fourier, BP 53, 38041 Grenoble, France (e-mail: serge.cosnier@ujf-grenoble.fr).

Digital Object Identifier 10.1109/JSEN.2004.832858 a biofilm. Then, the sensor is exposed to the sample (blood or other biological fluid); if antigen is present, an antigen-antibody complex will be formed. This formation will induce some changes of physicochemical parameters (usually mass, optical, or electrical parameters) of biofilm on the transducer surface, and that change can be subsequently detected. Depending on the transducer technology used, immunosensors can be divided into three principal classes: optical [3], [4], piezoelectric [5], [6], and electrochemical [7], [8]. Regardless of the transduction principle, the coupling of the molecular recognition receptor to the transducer surface is of key importance for the control and the improvement of the characteristics of the derivative sensor.

Thus, in the last 40 years, considerable attention has been focused on conducting polymers because of their unusual electronic properties and their great potential for biomolecule immobilization. Actually, several immobilization procedures based on conducting polymers [9]-[11] were used to ensure the coupling of immuno species. They range from an entrapment within the polymer film [12], [13] to an electrostatic binding [14]. Many industrial applications of biosensors demand stable and defined binding of biomolecules to surfaces according easy and reproducible processes [15], [16]. Thus, some methods take advantage of specific interactions between avidin or streptavidin and biotin to immobilize biomolecules modified by methods of molecular biology in a highly oriented way [17].

Recently, in order to preserve their recognition properties, the immobilization of proteins on electrodeposited polymer film has been attempted using affinity system [18], [19] such as biotin-avidin.

Avidin, found in hen egg white, is a very fascinating protein because of its extraordinarily high binding affinity for biotin. In fact, avidin exhibits the highest known affinity constant Ka in nature between a protein and a ligand $\left(\mathrm{Ka} \sim 10^{15} \mathrm{M}^{-1}\right)$ [20]. Owing to its high affinity, the avidin-biotin system has been used for coupling proteins to biotinylated polymer films. Therefore, the attachment of proteins was achieved via the formation of an avidin-biotin bridge with biotin or avidin conjugated proteins. This method allowed a high control over the molecule orientation, which is an important parameter for the improvement of the immunosensor characteristics. This immobilization method was already used by other authors [21] to ensure the attachment of glucose oxidase to a glassy carbon electrode.

In this report, we have used the latter method to immobilize the antibodies on prefunctionnalized gold electrodes. A 


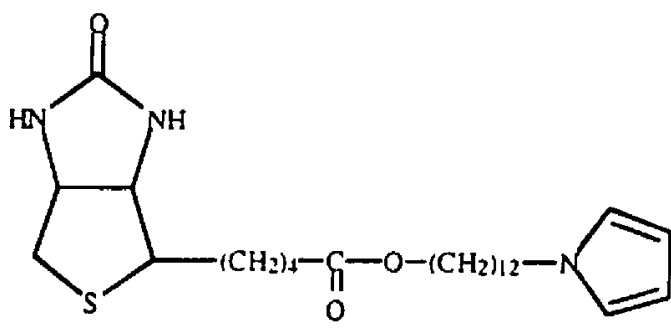

Fig. 1. Structure of the pyrrole biotin.

polypyrrole bearing biotin functions was electrodeposited on gold electrode and used for the subsequent antibody immobilization. The understanding of behavior and properties of the immunofunctionalized layers would allow a better approach of the key parameters involved for the optimization of the resulting immunosensor. In this aim, the properties of the polymeric layers including immunospecies have been studied in terms of permeability and electrochemical properties. Then, the performances of the impedimetric immunosensor based on biotinylated polypyrrole functionalized gold electrodes were studied.

\section{EXPERIMENTAL}

\section{A. Materials}

The antibody used was a polyclonal anti-human IgG developed in goat ( $\gamma$-chain specific), biotin conjugate, purchased from Sigma. The antigen was a human IgG reagent grade, from serum, purchased from Sigma. Bovine serum albimun (BSA, Fraction V, 96\%), from Sigma, was used to avoid nonspecific adsorption phenomena. The pyrrole biotin (Fig. 1) used in this work was synthesized as previously described in [21].

The supporting electrolyte was a phosphate buffer solution (PBS), prepared by dissolving one tablet of phosphate buffer saline, purchased from Sigma, in $200 \mathrm{ml}$ of desionized water. The obtained solution consisted of a $10-\mathrm{mM}$ phosphate buffer, 2.7-mM potassium chloride, and 137-mM sodium chloride. The $\mathrm{pH}$ solution at $25^{\circ} \mathrm{C}$ was 7.4.

A solution of $0.1-\mathrm{M}$ glycine and $0.4-\mathrm{M} \mathrm{NaCl}$ was prepared by dissolution of the reagents in distilled water. The $\mathrm{pH}$ was adjusted to 2.3 by titration with $\mathrm{HCl}$. This high ionic strength acidic solution was used systematically to dissociate the antigen-antibody complexes and so to regenerate the recognition surface of the sensor. The solution was stored in the range 0 to $5{ }^{\circ} \mathrm{C}$.

\section{B. Electrochemical Instrumentation and Procedure}

The electrochemical experiments were performed with an EG\&G Princeton Applied Research 273A potenstiostat connected to a Kipp and Zonen BD90 XY|t recorder. The electropolymerization process was run in a conventional three-electrode cell under argon atmosphere at room temperature. A $10 \mathrm{mM} \mathrm{Ag} \mid \mathrm{A}_{\mathrm{g}}^{+}$in $\mathrm{CH}_{3} \mathrm{CN}$ electrode, platinum foil, and a gold plate were used as reference electrode, auxiliary electrode, and working electrode respectively.

The impedimetric measurements were performed in a classic electrochemical cell, with three electrodes and a volume of $3.5 \mathrm{ml}$. The counter electrode was made of a platinum plate with an active surface of $0.48 \mathrm{~cm}^{2}$, whereas the active surface of the working gold plate electrode, fixed by an O-ring seal, was $0.16 \mathrm{~cm}^{2}$. The polarization of the working electrode was fixed against a saturated calomel reference electrode (SCE), purchased from Radiometer Analytical S.A.

\section{Modified Electrode Preparation}

First, the gold plate electrodes were cleaned for about $10 \mathrm{~min}$ in an etching solution: $1 / 4\left(\mathrm{H}_{2} \mathrm{O}_{2} 35 \%\right) 3 / 4\left(\mathrm{H}_{2} \mathrm{SO}_{4} 96 \%\right.$. Immediately after, the pretreated electrodes were thoroughly rinsed with desionized water in order to remove any deposited impurities, and then dried under a stream of nitrogen. The electrogeneration of the biotinylated polypyrrole film was performed by electrooxidation of the monomer $(2 \mathrm{mM})$ at $0.85 \mathrm{~V} / \mathrm{Ag} \mid \mathrm{A}_{\mathrm{g}}^{+}$ in acetonitrile solution containing $0.1 \mathrm{M}$ TBAP (Tetrabutylammonium perchlorate) as a supporting electrolyte. The specific binding of avidin to polymer biotin sites was achieved via the incubation of the subsequent functionalized gold electrodes in a $2 \mathrm{mg} \mathrm{ml}^{-1}$ avidin solution, for $30 \mathrm{~min}$ at $5^{\circ} \mathrm{C}$. The obtained electrodes were carefully rinsed with PBS.

The former electrodes were incubated in a solution of biotinylated antibody (anti-human $\mathrm{IgG}$ ) at a concentration of $1 \mathrm{mg} \mathrm{ml}^{-1}$ during $12 \mathrm{~h}$ at $5^{\circ} \mathrm{C}$. These electrodes were then thoroughly rinsed with a PBS solution to remove weakly adsorbed antibodies. Finally, the resulting electrode was exposed to a known concentration of antigen.

\section{Impedance Measurements}

The various steps of the fabrication of the sensor were controlled by impedance spectroscopy. An impedance analyzer Voltalab 4 from Radiometer Analytical Instrument S.A., controlled by computer, was used to measure the total ac impedance of the electrochemical cell. These measurements were carried out by scanning the frequency from $10^{-2}$ to $10^{5} \mathrm{~Hz}$, acquiring five points per decade. An excitation voltage of $5 \mathrm{mV}$ was over imposed [22], [23]. All measurements were performed in PBS containing $5 \%$ of $\mathrm{BSA}$, at room temperature.

\section{E. Atomic Force Microscopy (AFM)}

AFM experiments were carried out using a Nanoscope III (Digital Instruments, Santa Barbara, CA) operating under a contact mode in air. We used triangular $\mathrm{Si}_{3} \mathrm{~N}_{4}$ mirocantilever (Nanoprobe, NP-S, Digital Instruments) with a spring constant of $0.06 \mathrm{Nm}^{-1}$.

\section{RESULTS AND DISCUSSION}

The electropolymerization of the biotinylated polypyrrole was achieved by controlled potential oxidation at $0.8 \mathrm{~V}$ to avoid the overoxidation of the polypyrrole and hence to preserve its conductivity [24]. The resulting electrode was transferred, after thoroughly rinsing, to a $\mathrm{CH}_{3} \mathrm{CN}+0.1 \mathrm{M}$ TBAP solution free of monomer. Fig. 2 Shows a typical cyclic voltammogram obtained onto the polymer coated electrode. In the positive region, a reversible peak is recorded at $0.4 \mathrm{~V}$, corresponding to the oxidation of the polypyrrole matrix. This value is in good agreement with the reported $\mathrm{E}_{1 / 2}$ values for poly(N-alkylpyrroles) [25]. This indicates the formation of an 


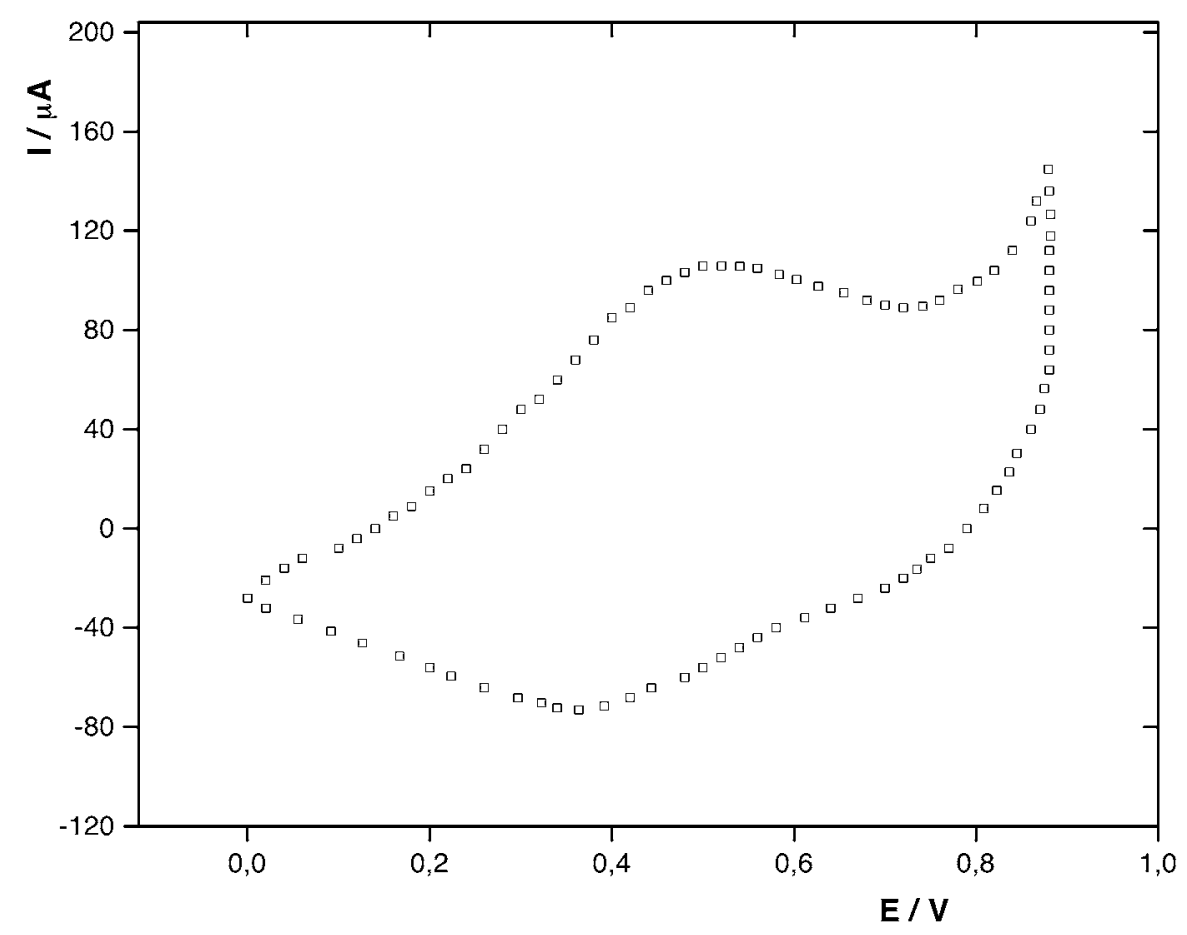

Fig. 2. Cyclic voltammogram of Au|poly(pyrrole biotin) electrode in $\mathrm{CH}_{3} \mathrm{CN}+0.1 \mathrm{M}$ TBAP, scan rate $50 \mathrm{mV} \mathrm{s}^{-1}$.

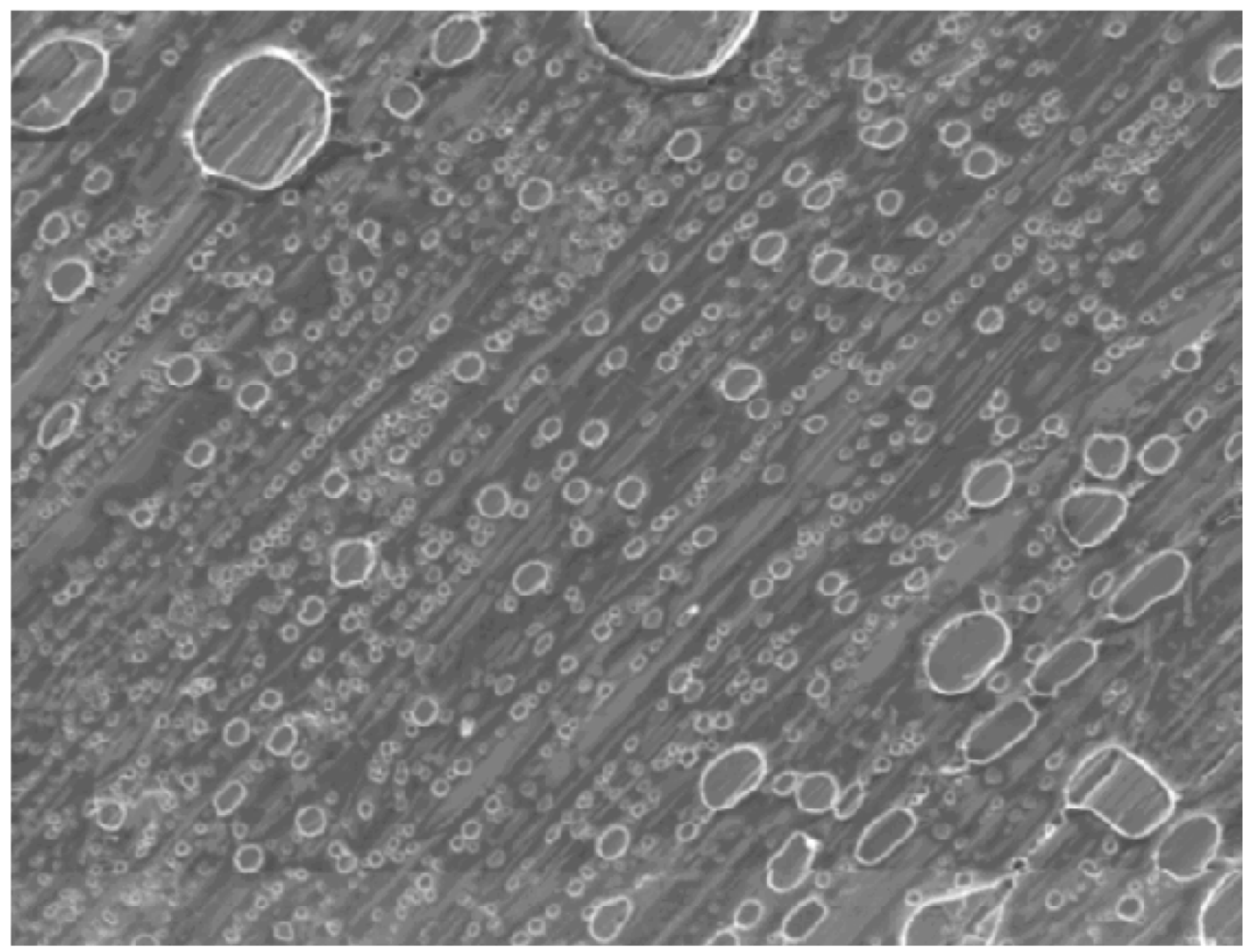

Fig. 3. SEM micrograph $(\times 600)$ of poly(pyrrole biotin) electrodeposited on gold electrode.

electropolymerized film of poly(CEPy) on the electrode surface as a consequence of the pyrrole oxidation. The apparent surface coverage $\Gamma=2.7 \times 10^{-8} \mathrm{~mol} \mathrm{~cm}^{-2}$ was determined from the charge recorded under the polypyrrole oxidation wave tacking into account that the electrooxidation of the polypyrrole chain corresponds to 0.33 electron $\mathrm{mol}^{-1}$ [26] 


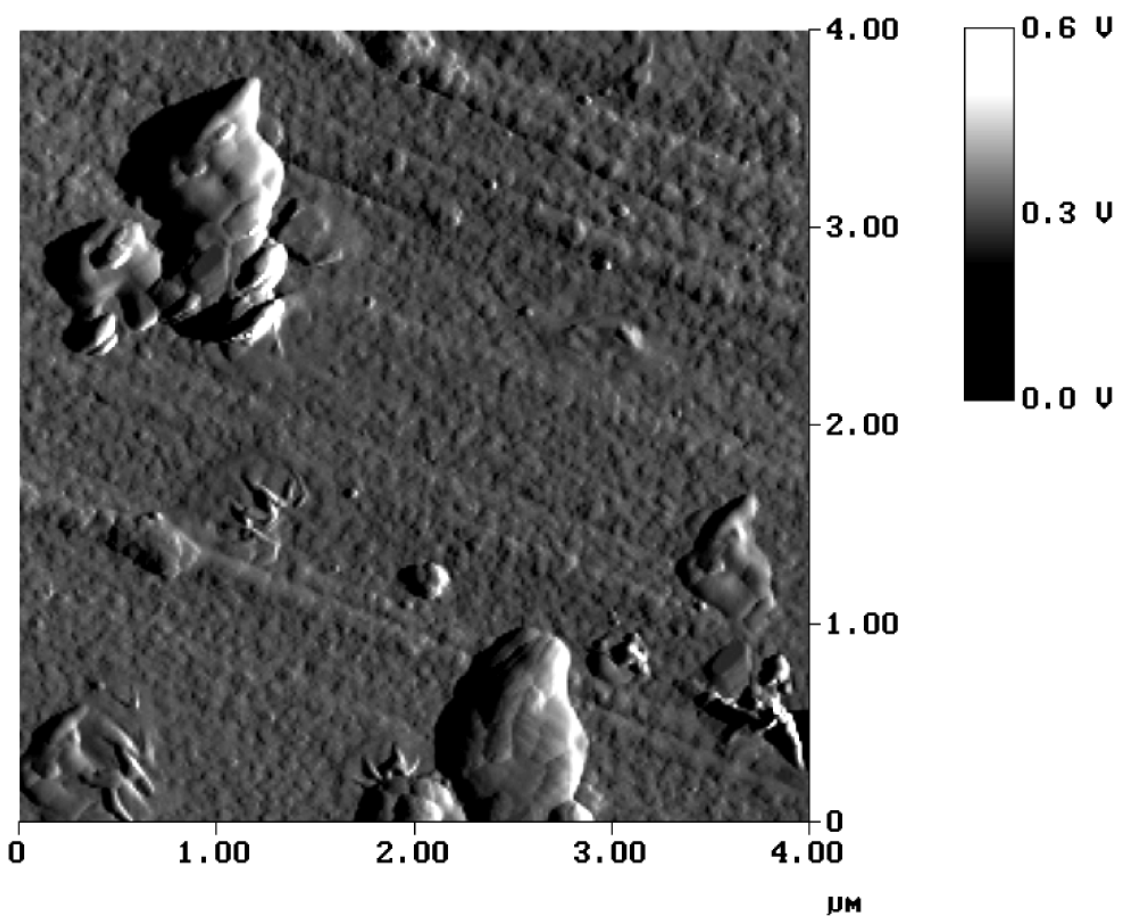

Fig. 4. AFM image in contact mode of poly(pyrrole biotin) film electrodeposited on gold electrode.
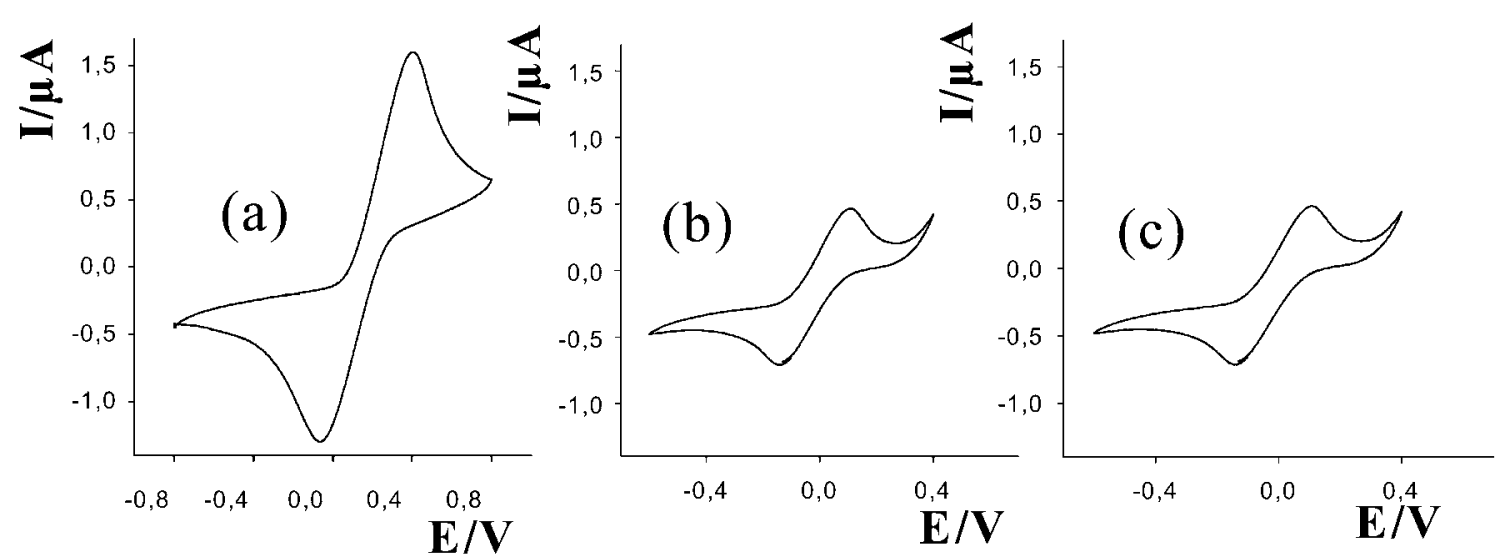

Fig. 5. Cyclic voltammograms of 10-mM ferroccyanide in PBS on (a) a bare gold electrode, (b) a poly(pyrrole biotin) electrode, and (c) a poly(pyrrole biotin) electrode with Avidin, scan rate $0.1 \mathrm{~V} \mathrm{~s}^{-1}$.

In addition, the morphology of the polymer-coated electrode was monitored by both atomic force microscopy (AFM) and scanning electron microscopy (SEM). Fig. 3. presents the texture of the polymer film, carried out by SEM. So, the SEM micrograph of the polypyrrole biotin deposited on gold electrode, exhibits a randomly distribution of polymer clusters with different sizes (Fig. 3). This character is evenly highlighted on the AFM image shown in Fig. 4, which illustrates that the coverage of electrode surface is not homogeneous.

Additionally, further characterization, using permeation measurements, was carried out to evaluate the effectiveness of each step in the fabrication of the immunosensor. For this purpose, we have proceeded by recording cyclic voltammograms of ferrocyanide used as permeant electroactive probe. Thus, the cyclic voltammetry experiments were carried out in a PBS solution containing $10 \mathrm{mM}$ of both $\mathrm{K}_{3}\left[\mathrm{Fe}(\mathrm{CN})_{6}\right]$ and $\mathrm{K}_{4}\left[\mathrm{Fe}(\mathrm{CN})_{6}\right]$. Fig. 5 presents the cyclic voltammograms rela- tive to the different modification steps. As it clearly observed in Fig. 5, the difference between the gold bare electrode and the polymer-coated electrode voltammograms is obvious. Hence, the electrodeposited polymer covers the surface of the electrode and the access of the redox couple is hindered. Nevertheless, the faradaic process of oxidation and reduction of the redox couple $\left[\mathrm{Fe}(\mathrm{CN})_{6}\right]^{4-/ 3-}$ is only partially inhibited after the deposition of the polymer film. This suggests the existence of pinholes in the dense polymer film, through which the redox couple can pass toward the gold surface. The clusters observed by SEM and AFM are formed on this dense polymer film. In contrast, the immobilization of avidin does not cause any significant additional variation in the voltammogram spectra.

It is well established that the polymer state (conducting or insulator) is quite dependent on the potential value [27]. In addition, the diffusion phenomena, taking place at low frequency, 


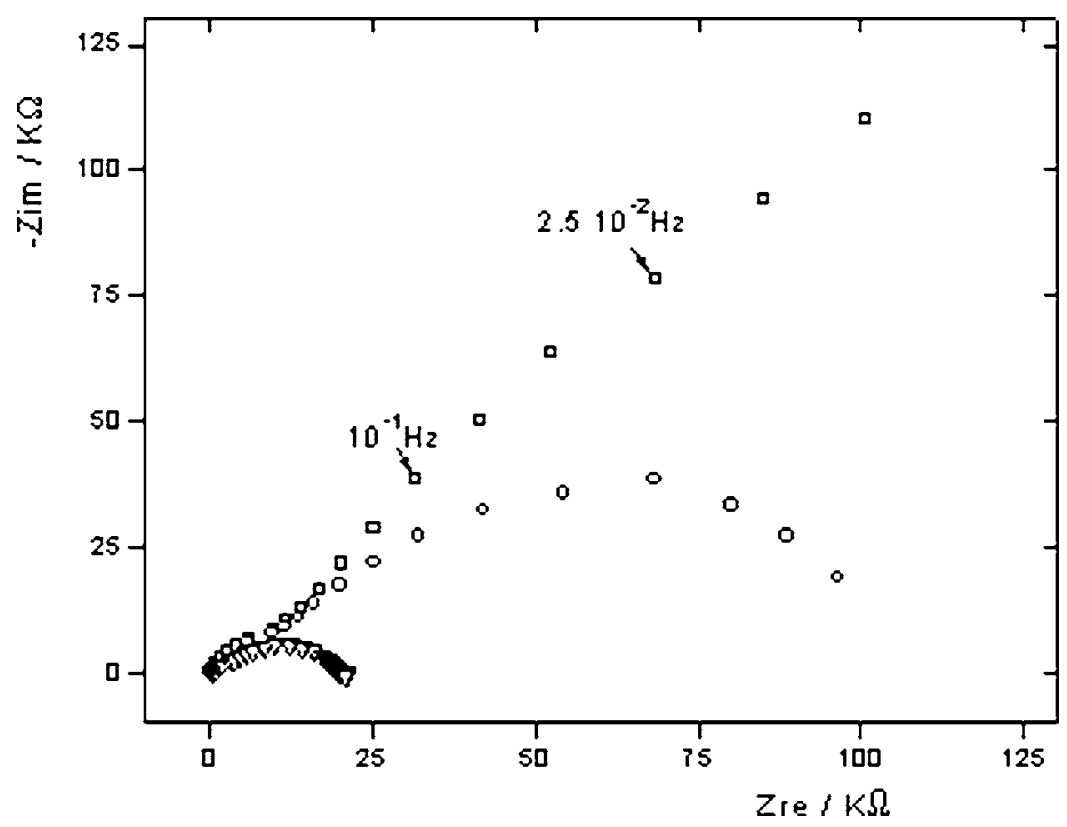

Fig. 6. Complex plane impedance spectra obtained for gold electrode functionnalized by electropolymerization of the pyrrole biotin at three different potentials. $\square: 0$ V. O: $-1.3 \mathrm{~V} . \nabla:-1.4 \mathrm{~V}$.

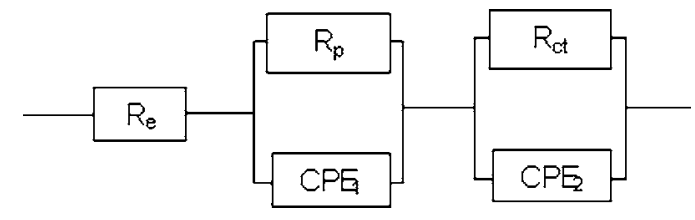

Fig. 7. Equivalent electrical circuit used in the theoretical fit of the impedance diagram of the polymer-coated electrode at a bias potential $-1.4 \mathrm{~V}$.

could mask the specific antibody-antigen interaction, which also takes place at the same frequency range. So, it will be necessary to minimize the former phenomena in order to allow the latter phenomenon to appear. For this purpose, the impedance of the polymer-coated electrode was recorded at different bias voltage (Fig. 6). The impedance measurements show typical curves for polypyrrole films deposited on metal [28]. For all potentials, a semicircle is present at high frequency. Whereas, in the low-frequency region, next to the first semicircle, a straight line having a slope at an angle higher than $45^{\circ}$ to the real axis, reflecting both diffusion phenomena and/or the roughness of the electrode surface. This behavior is attenuated with the decrease of the bias potential and vanished quasitotally at a potential of $-1.4 \mathrm{~V}$. Therefore, this latter potential was chosen for the following studies.

The electrochemical behavior of the polymer-coated electrode, under a bias potential of -1.4 , was simulated by the electrical equivalent circuit of Fig. 7, which was found to give the best fit results. The two R and CPE (constant phase element) combinations correspond to the two depressed semicircles. Where $R_{e}$ is the electrolyte resistance, $R_{p}$ and $C P E_{1}$ are the parameters which characterize the polymer film, $\mathrm{CPE}_{2}$ is a constant phase element which substitutes the well-known double layer capacitance $\left(\mathrm{C}_{\mathrm{dl}}\right)$ and which takes into account the phenomena related to the roughness of the electrode surface and diffusion processes [29], and $\mathrm{R}_{c t}$ is the charge transfer resistance. Curve fitting of the experimental result was performed with the program "EQUICRVT" [30] (Fig. 8).

The ability of the polymer film for the immobilization of biotinylated antibodies via the formation of avidin-biotin bridge has been tested by impedance spectroscopy. For this purpose, the impedance of the polymer layer, for the successive bindings of the avidin and antibody (anti-human IgG) has been recorded (Fig. 9). The diameter of the second semicircle is shown to increase after immobilization of avidin, as well as after immobilization of the antibody. This clearly indicates the binding of avidin to biotin groups of the polymer film and then the binding of biotiylated antibodies to avidin.

In order to decrease nonspecific effects, $5 \%$ of BSA was permanently present in the buffer solution. The antibody-functionalized electrode was exposed to different concentrations of antigen (human IgG reagent). As shown in Fig. 10, the second semicircle diameter in the Nyquist plot seems to increase with increasing the antigen concentration. Another possible representation of the impedance spectra is the so-called Bode plot. In this representation, it appears that the major changes in the impedance character occurred at low frequency (Fig. 11). This means that the most significant change of the electrochemical properties of the biofilm takes place at low frequency. Therefore a frequency of $40 \mathrm{mHz}$ appears to be suitable for concentration-dependent impedance measurements.

In order to obtain a calibration curve for the sensor, the variation of $\log \left(|Z| /\left|Z_{0}\right|\right)$ was plotted versus the values of the antigen concentration at frequency of $0.04 \mathrm{~Hz}$, where $\left|Z_{0}\right|$ is the modulus of the impedance of the antibody modified electrode before the injection of antigens and $|Z|$ is that of the same electrode after each antigen addition. A typical calibration curve for antigen is shown in Fig. 12.

This calibration curve was quasilinear with antigen concentration from 10 to $80 \mathrm{ng}$, and then curved gradually at higher 


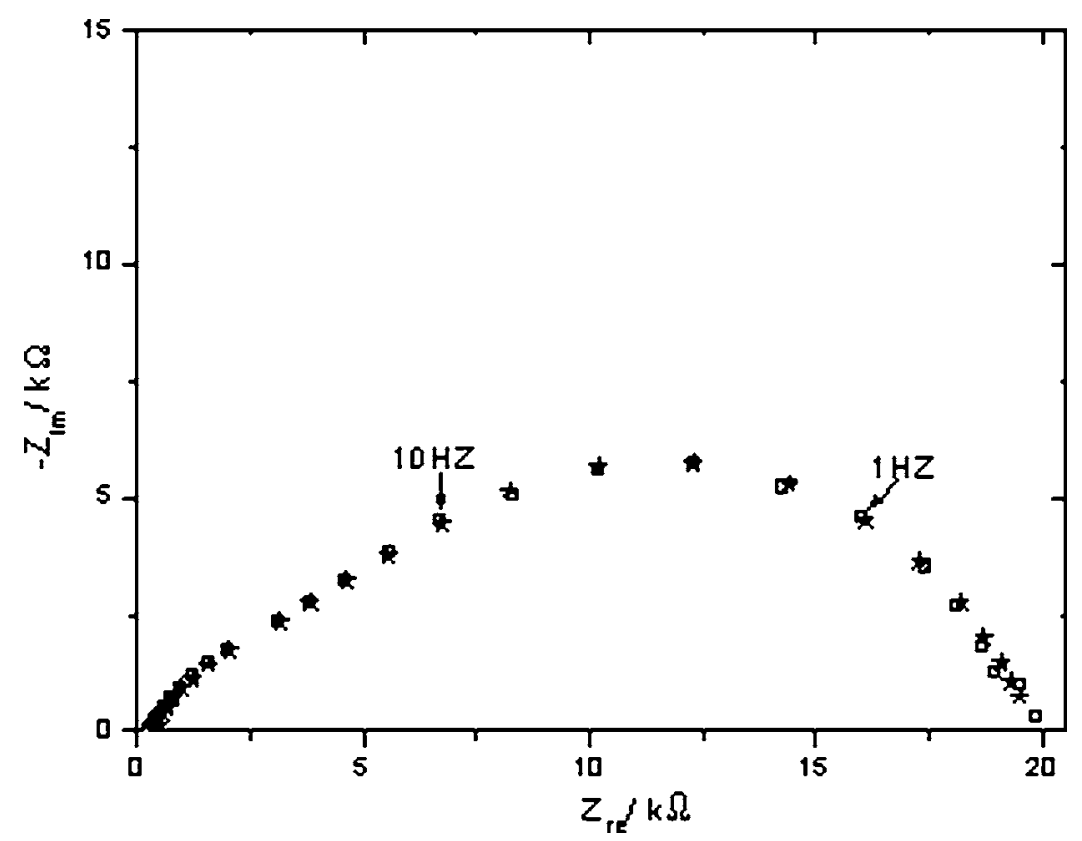

Fig. 8. (O) Experimental and $(*)$ calculated impedance plots obtained for a polymer-coated electrode at bias potential $-1.4 \mathrm{~V}$.

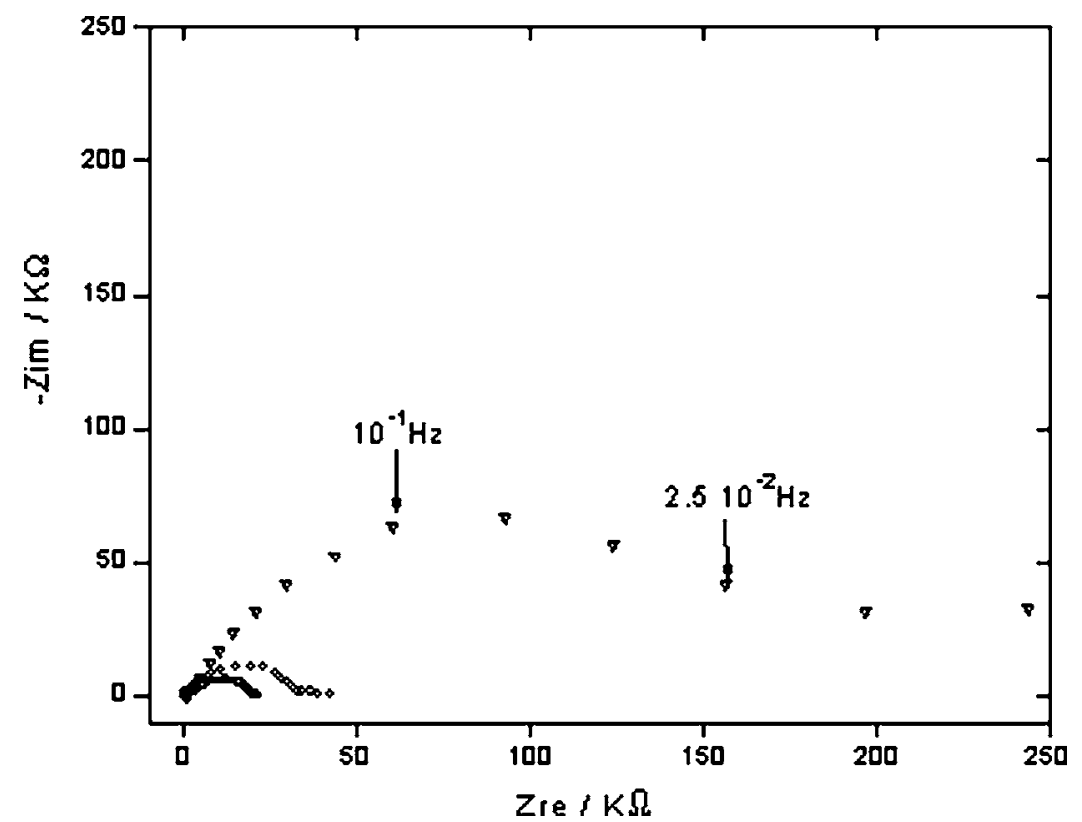

Fig. 9. Complex plane impedance plots for a bare gold electrode after different modification steps. $\square$ : After electrodeposition of the poly(pyrrole biotin) film. O: after immobilization of avidin. $\Delta$ : After immobilization of the antibody.

concentrations. Therefore, the immunosensor had a linear dynamic range from 10 to $80 \mathrm{ng} \mathrm{ml}^{-1}$ and a detection limit of about $10 \mathrm{pg} \mathrm{ml}^{-1}$. The former limited dynamic range can be explained by the poor electropolymerization ability of the biotin pyrrole derivative. So, only few biotin sites could be generated. To overcome this drawback, copolymerization of pyrrole biotin with a pyrrole ammonium have been attempted, and layers with different thickness have been obtained. Unfortunately, the derivative electrodeposited film had poor stability in the solution used for immunosensing tests.

Since the antigen-antibody binding is mainly determined by the high degree of complement in steric structures between antigen epitopes and antibody paratopes, solutions such as acid, base, or salts of high ionic strength [31]-[33] could be used to split the immune complexes. Furthermore, it should be noted that the effect of an elution reagent depends on the elution time. Therefore, in order to split the antibody-antigen complex and, hence, to regenerate the recognition surface of the sensor, glycine buffer ( $\mathrm{pH}$ 2.3) was applied for $3 \mathrm{~min}$. Such protocol was, already, shown to be efficient by other authors [34]. Next, the electrode was washed with PBS. As unexpected, the sensitivity of the sensor, given as the slope of the linear part of the calibration curve, increased after the first regeneration (Fig. 12). Such a surprising result was already found by other authors using classical immunosensing tests (ELISA) [35]. This unexpected phenomenon can be explained, in part, by 


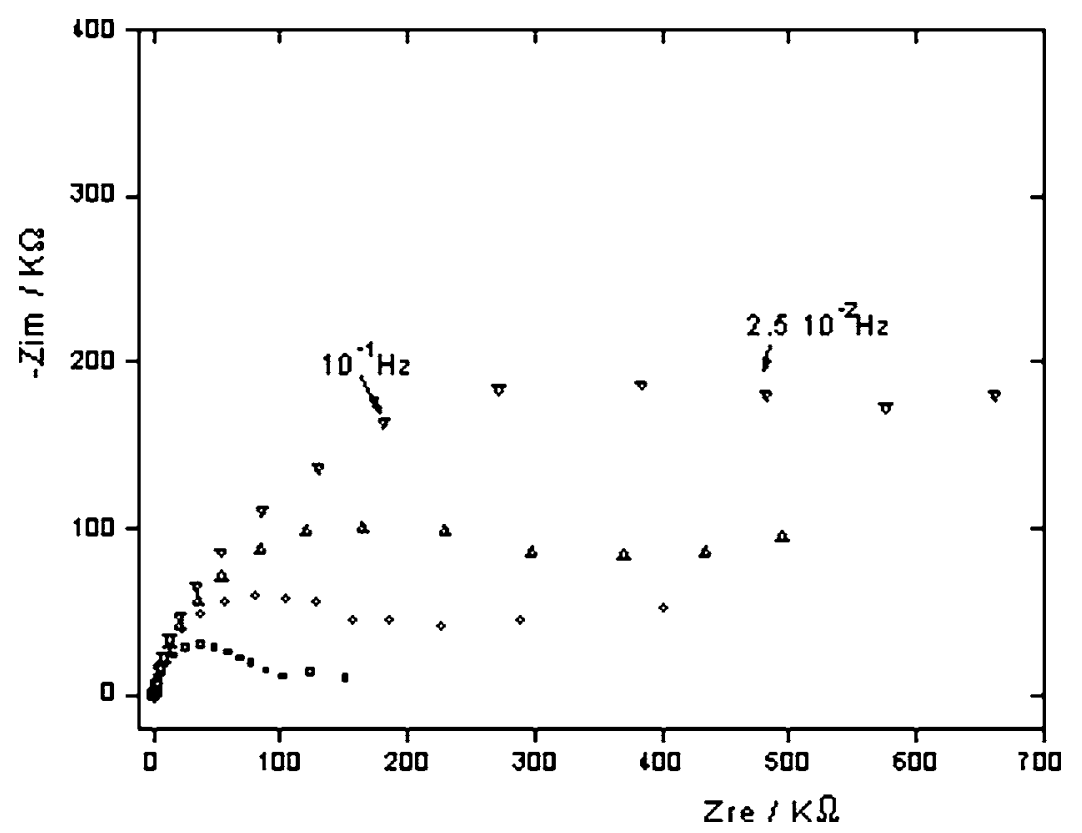

Fig. 10. Complex plane impedance plots obtained for an antibody modified electrode at a potential of $-1.4 \mathrm{~V}$ versus SCE and ac signal of $5 \mathrm{mV}$, in PBS. $\square$ Without antigen injection; after antigen injection at different concentrations. O: $10 \mathrm{ng} \mathrm{ml}^{-1} . \Delta: 50 \mathrm{ng} \mathrm{ml}^{-1} . \nabla: 90 \mathrm{ng} \mathrm{ml}^{-1}$.

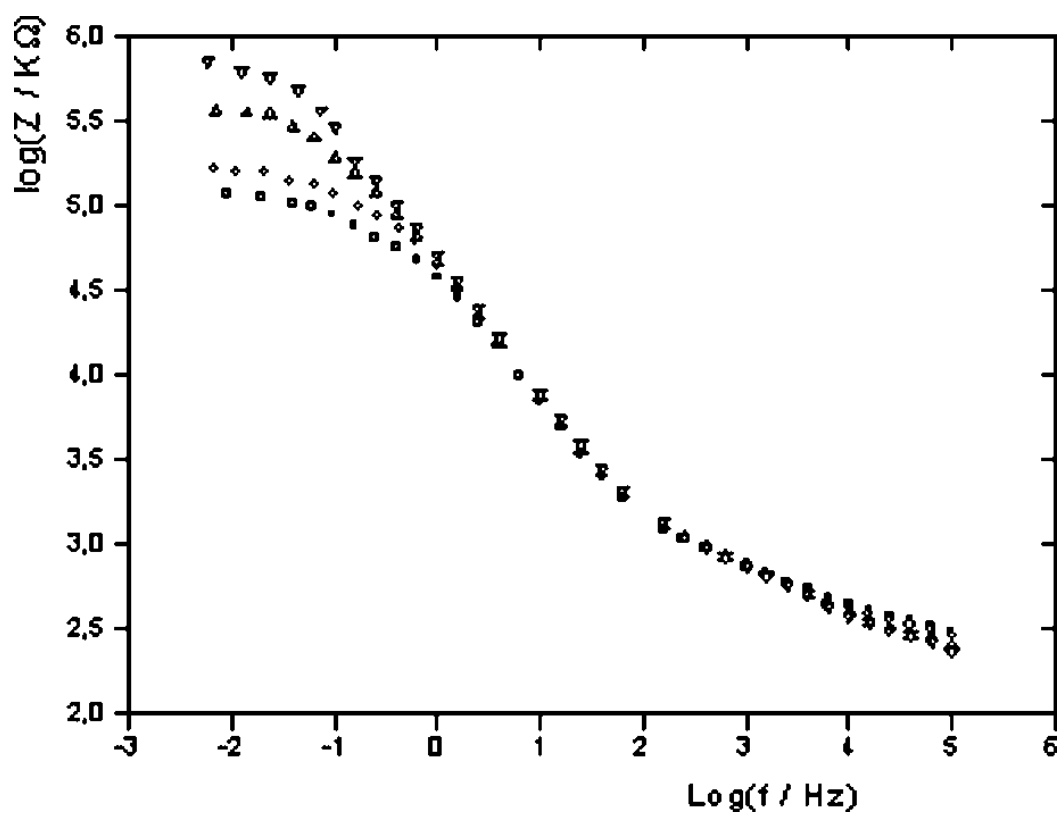

Fig. 11. Bode plane impedance spectra obtained for an antibody modified electrode at a potential of $-1.425 \mathrm{~V}$ versus SCE and ac signal of $5 \mathrm{mV}$, in PBS. $\square$ : without antigen injection; after antigen injection at different concentration. O: $10 \mathrm{ng} \mathrm{ml}^{-1} . \Delta .50 \mathrm{ng} \mathrm{ml}^{-1} . \nabla: 90 \mathrm{ng} \mathrm{ml}^{-1}$.

the improvement of the accessibility of the binding sites of the antibody after short-time acidic washing, whereas repeated acidic washing of the sensing layer may reduce the activity of the antibody, which can explain the decrease of the sensitivity of the sensor after the second regeneration.

\section{CONCLUSION}

A biotin-avidin system has been used to immobilize biotinylated antibodies on gold electrode-functionalized by electropolymerized biotinylated polypyrrole in order to conceive an impedimetric immunosensor. Commercial anti-human $\mathrm{IgG}$, biotin conjugated, was used as a model system. The sensor, exhibits a dynamic range $10-80 \mathrm{ng} \mathrm{ml}^{-1}$ and a detection limit of $10 \mathrm{pg} \mathrm{ml}^{-1}$. Furthermore, the regeneration of the sensing biolayer was successfully reached using an acidic solution. In future work, different ways will be tested in order to enlarge the dynamic range of this sensor: increasing density of biotin groups on the electropolymerized pyrrole film, piling up of several biotinylated antibody layers with successive avidin treatments. 


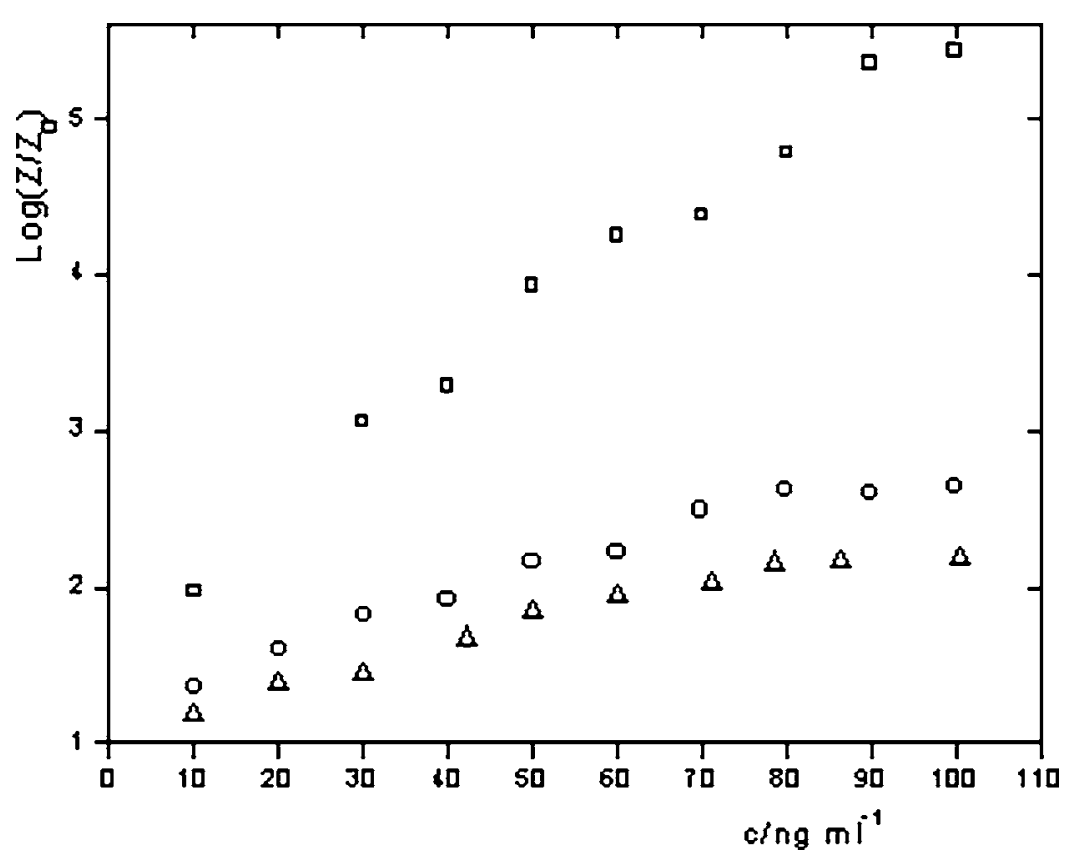

Fig. 12. Response curve of the sensor, applied potential $-1.4 \mathrm{~V}$ versus SCE, frequency $0.04 \mathrm{~Hz}$, and $0.01 \mathrm{M}$ PBS (pH 7.2). O: First usage. $\square$ : after the first regeneration. $\Delta$ : After a second regeneration.

\section{REFERENCES}

[1] E. Gizeli and C. R. Lowe, "Immunosensors," Curr. Opt. Biotech., vol. 7, pp. 66-71, 1996.

[2] A. P. F. Turner, "Biosensors," Cur. Opt. Biotech., vol. 5, pp. 49-53, 1994.

[3] I. Lundström, "Real-time biospecific interaction analysis," Biosens. Bioelectron., vol. 9, pp. 725-736, 1994.

[4] D. Yeung, A. Gill, C. Maule, and R. J. Davies, "Detection and quantification of biomolecular interactions with optical biosensors," Trends Anal. Chem., vol. 14, pp. 49-56, 1995.

[5] N. J. Geddes, E. M. Paschinger, D. N. Furlong, F. Caruso, C. L. Hoffmann, and J. F. Rabolt, "Surface chemical activation of quartz crystal microbalance gold electrodes-analysis by frequency changes, contact angle measurements and grazing angle FTIR," Thin Solid Films, vol. 260, pp. 192-199, 1995.

[6] A. A. Suleiman and G. G. Guilbault, "Recent developments in piezoelectric immunosensors," The Analyst, vol. 119, pp. 2279-2282, 1994.

[7] M. V. Mirsky, M. Riepl, and O. S. Wolfbeis, "Capacitive monitoring of protein immobilization and antigen-antibody reactions on monomolecular alkylthiol films on gold electrodes," Biosens. Bioelectron., vol. 12, pp. 977-989, 1997.

[8] F. Patolsky, B. Filanovsky, E. Katz, and I. Willner, "Photoswitchable antigen-antibody interactions studied by impedance spectroscopy," J. Phys. Chem. B Mater. Surf. Interfaces Biophys., vol. 102, pp. 10359-10367, 1998 .

[9] S. Cosnier, "Biomolecule immobilization on electrode surfaces by entrapment or attachment to electrochemically polymerized films," Biosens. Bioelectron., vol. 14, pp. 443-456, May 1999.

[10] A. Sargent and O. A. Sadik, "Monitoring antibody-antigen reactions at conducting polymer-based immunosensors using impedance spectroscopy," Electrochim. Acta, vol. 44, pp. 4667-4675, Sept. 1999.

[11] R. A. Porter, "Investigation of electroplated conducting polymers as antibody receptors in immunosensors," J. Immunoassay, vol. 21, pp. 51-64, 2000.

[12] S. Uchiyama, Y. Hasebe, and M. Tanaka, "L-ascorbate sensor with an immobilized ascorbate oxidase carbon felt prepared by electropolymerization of pyrrole in cucumber juice," Electroanal., vol. 9, pp. 176-178, 1997.

[13] K. Habermüller and W. Schuhmann, "A low-volume electrochemical cell for the deposition of conducting polymers and entrapment of enzymes," Electroanal., vol. 10, pp. 1281-1284, Feb. 1998.

[14] O. Ouerghi, A. Senillou, N. Jaffrezic-Renault, C. Martelet, H. Ben Ouada, and S. Cosnier, "Gold electrode functionalized by electropolymerization of a cyano N-substituted pyrrole: application to an impedimetric immunosensor," Electroanal. Chem., vol. 501, pp. 62-69, Mar. 2001.
[15] T. F. Christiansen and K. M. Jacobsen, Acta Anaesthol. Scand. Suppl., vol. 39, pp. 31-35, 1995.

[16] S. Löfas and B. Johnsson, "A novel hydrogel matrix on gold surface in surfaces plasmon resonance sensors for fast and efficient covalent immobilization of ligands," J. Chem. Soc., Chem. Comm., pp. 1526-1528, 1990.

[17] M. Hengsakul and A. E. G. Cass, "Protein patterning with a photoactivatable derivative of biotin," Bioconjugate Chem., vol. 7, pp. 249-254, Mar. 1996.

[18] S. T. Yang, A. Witkowski, R. S. Hutchins, D. L. Scott, and I. G. Bachas, "Biotin-modified surfaces by electrochemical polymerization of biotinyl-tyramide," Electroanal., vol. 10, pp. 58-60, Dec. 1998.

[19] S. Cosnier and A. Lepellec, "Poly(pyrrole-biotin): a new polymer for biomolecule grafting on electrode surfaces," Electrochim. Acta, vol. 44, pp. 1833-1836, 1999.

[20] M. Wilchek and E. A. Bayer, "Avidin-biotin technology ten years on: has it lived up to its expectations?," Trends Biochem. Sci., vol. 14, pp. 408-412, Oct. 1989.

[21] S. Cosnier, M. Stoytcheva, A. Senillou, H. Perrot, R. P. M. Furriel, and F. A. Leone, "A biotinylated conducting polypyrrole for the spatially controlled construction of an amperometric biosensor," Anal. Chem., vol. 71, pp. 3692-3697, 1999.

[22] K. Darowicki, "The amplitude analysis of impedance spectra," Electrochim. Acta, vol. 40, pp. 439-445, Mar. 1995.

[23] J. P. Diard, B. Le Gorrec, and C. Montella, "Impedance measurements errors due to nonlinearities-I. Low frequency impedance measurements," Electrochim. Acta, vol. 39, pp. 539-546, Mar. 1994.

[24] H. Röckel, J. Huber, R. Gleiter, and W. Schuhmann, "Synthesis of functionalized ply(dithienylpyrrole) derivatives and their application in amperometric biosensors," Adv. Mater., vol. 6, pp. 567-571, 1994.

[25] A. F. Diaz, J. Castillo, K. K. Kanazawa, J. A. Logan, M. Salmon, and O. Fajardo, "Conducting poly- $N$-alkylpyrrole polymer films," J. Electroanal. Chem., vol. 133, pp. 233-239, Feb. 1982.

[26] A. Deronzier and J. C. Moutet, Acc. Chem. Res., vol. 22, p. 249, 1989.

[27] P. Ferloni, M. Mastragostino, and L. Meneghello, "Impedance analysis of electronically conducting polymers," Electrochim. Acta, vol. 41, pp. 27-33, Jan. 1996.

[28] S. Panero, P. Prosperi, and B. Scrosati, "Properties of electrochemically synthesized polymer electrodes-IX. The effects of surfactants on polypyrrole films," Electrochim. Acta, vol. 37, pp. 419-423, Mar. 1992.

[29] J. R. Macdonald, Impedance Spectroscopy. New York: Wiley, 1987.

[30] B. A. Boukamp, "Equivalent Circuit," University of Twente, Twente, The Netherlands, Rep. CT88/265/128, CT89/214/128, 1989. 
[31] D. A. Mann, M. Kanai, D. J. Maly, and L. L. Kiessling, "Probing low affinity and multivalent interactions with surface plasmon resonance: ligands for concanavalin A," J. Amer. Chem. Soc., vol. 120, pp. 10575-10582, 1998.

[32] S. S. Taremi, W. W. Prosise, N. Rajan, R. A. O'Donnell, and H. V. Le, "Human interleukin 4 receptor complex: neutralization effect of two monoclonal antibodies," Biochem., vol. 35, pp. 2322-2331, Feb. 1996.

[33] T. C. Vancott, L. D. Loomis, R. R. Redfield, and D. L. Birx, "Real-time biospecific interaction analysis of antibody reactivity to peptides from the envelope glycoprotein, GP 160, of HIV-1," J. Immunol. Meth., vol. 146, pp. 163-176, 1992.

[34] R. Pei, X. Cui, X. Yang, E. Wang, and E. Talanta, Real-Time Immunoassay of Antibody Activity in Serum by Surface Plasmon Resonance Biosensor, vol. 53, pp. 481-699, Dec. 2000.

[35] V. Billard, C. Martelet, P. Binder, and J. Therasse, "Toxin detection using capacitance measurements on immunospecies grafted onto a semiconductor substrate," Anal. Chim. Acta, vol. 249, pp. 367-372, 1991.

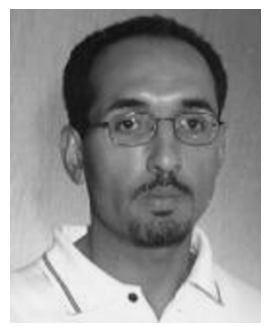

Oussama Ouerghi received the high degree in quantum physics from the University of Sciences of Tunis, Tunisia, in 1995. He is currently pursuing the Ph.D. degree at the Laboratory of Physics and Chemistry of Interfaces, University of Sciences, Monastir, Tunisia.

His research activities concern the characterization and optimization of immunosensors by means of AFM and EIS.

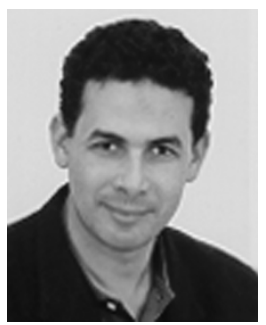

Ahmed Touhami is a Research Associate in physics department at Dalhousie University, Halifax, NS, Canada. His research interests include the characterization of the structural and physical properties of living microbial cells by atomic force microscopy, the creation of nanobiostructures by self-assembly, and the manipulation of single biomolecules.

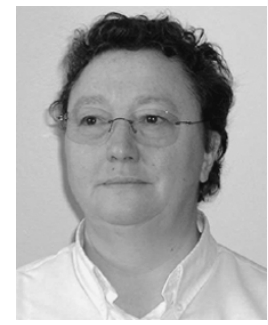

Nicole Jaffrezic-Renault received the engineering degree from the Ecole Nationale Superieure de Chimie, Paris, France, in 1971 and the Doctorat d'Etat és Sciences Physiques from the University of Paris in 1976

Since 1971, she has been a Research Worker at the Center National de la Recherche Scientifique. In 1984, she joined the Ecole Centrale de Lyon, Ecully, France, where she is in charge of the Chemical Sensor Group. Since 1997, she has been the President of the Chemical Microsensor Club in France. Her research activities concern the preparation and the physicochemical characterization of the recognition part of electrochemical and optical sensors.

Claude Martelet received the engineering degree from the Institut de Chimie et Physique Industrielle de Lyon, Lyon, France, in 1967 and the Doctorate degree from the d'Etat ès sciences Physiques, France, in 1973.

$\mathrm{He}$ is a Professor at the Ecole Centrale de Lyon, Ecully, France. From 1967 until 1983, he worked in radioanalytical chemistry, microcalorimetry, and photoelectrochemistry. Since 1984, he has been working in the field of microchemicals and microbiosensors at the Ecole Centrale de Lyon. He is also Editor of the information letter of the French CMC2 (Chemical Micro Sensor Club)

Hafedh Ben Ouada received the Doctorat d'Etat ès sciences de Physiques in 1992.

He is a Professor at the University of Sciences of Manastir, Tunisia. He is currently Director of the Laboratory of Physics and Chemistry of Interfaces, University of Sciences, Monastir. His research interests include the characterization and the optimization of ions sensors, biosensensors, and the optoelectronic characterization of conductor polymers and their applications.

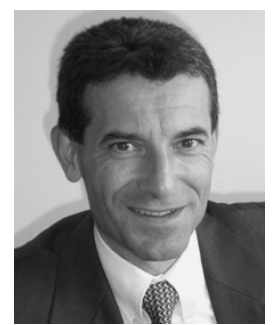

Serge Cosnier received the doctoral degree in chemistry from the University of Toulouse, Toulouse, France, 1982 and the Ph.D. degree from the University Joseph Fourier, Grenoble, France, in 1988.

$\mathrm{He}$ is the Director of Research at the Universite Joseph Fourier, where he heads the Bio-electrochemistry Team. Previously, he was an Alexander von Humbold postdoctoral fellow at Munich University, Munich, Germany. His present research interests include electrochemical biosensors, immunosensors and biochips, molecular electrochemistry, and electrogenerated conducting polymers. He is also Director of the CNRS unit GDR 2619 "Microbiosensors" and President of the French Group of Bioelectrochemistry. 